\title{
VEHICLE EMISSIONS AND DRIVING CYCLES: COMPARISON OF THE ATHENS DRIVING CYCLE (ADC) WITH ECE-15 AND EUROPEAN DRIVING CYCLE (EDC)
}

\author{
E.TZIRAKIS ${ }^{1 *}$ \\ K. PITSAS ${ }^{2}$ \\ F. ZANNIKOS ${ }^{1}$ \\ S. STOURNAS ${ }^{1}$
}

Received: 09/12/05

Accepted: 30/05/06

\author{
${ }^{1}$ Laboratory of Fuel Technology and Lubricants \\ Chemical Engineering Dept., NTUA \\ Iroon Polytechniou 915773 Zografou Athens, Greece \\ ${ }^{2}$ Ministry of Transport \\ Anastaseos 2 \& Tsigante \\ 10191 Holargos Athens, Greece
}

*to whom all correspondence should be addressed: e-mail: vtziraks@central.ntua.gr

\begin{abstract}
Vehicle emissions constitute the main source of atmospheric pollution in modern cities. The increasing number of passenger cars, especially during the last decade, resulted in composite traffic problems with serious consequences on emissions and fuel consumption. This project was carried out in the Laboratory of Fuel Technology and Lubricants at NTUA in order to examine the effects of the driving patterns on fuel consumption and exhaust emissions from cars in the Athens basin.

The typical driving profile consists of a complicated series of accelerations, decelerations and frequent stops and it is simulated by driving cycles on a laboratory chassis dynamometer. The New European Driving Cycle (NEDC) is applied in laboratory test approvals in the EU and is based on traffic data from European capitals (Paris and Rome). Traffic data from Athens was not included in the development of NEDC. The FTP 75 driving cycle and the Japan 10-15 modal cycle are currently used in the United States and Japan respectively. The different than other European cities and rapidly changing traffic conditions in Athens as well as the expanding transportation network and the atmospheric pollution problems impose the need to develop the Athens Driving Cycle (ADC).

In this paper, onboard electronic equipment (GPS, OBD II reader, accelerometer, etc) was used and "real world" traffic data was collected, covering almost all the Athens road network for a two year period. Dedicated software was developed for the statistical analysis of the recorded parameters and therefore the first ADC was modeled with the following characteristics: ADC duration is 1160 seconds, the overall distance is 6512 meters, the mean velocity is $20.21 \mathrm{~km} \mathrm{~h}^{-1}$ and the maximum velocity is $70.86 \mathrm{~km} \mathrm{~h}^{-1}$.

For comparison purposes, three passenger cars of different classification (Citroen Xsara 1.6L, a Mitsubishi Space Runner 2.0L Turbo and a Chrysler PT Cruiser 2.4L Turbo) were tested on a laboratory chassis dynamometer, applying three distinctive Driving Cycles: the Urban Driving Cycle (ECE-15), the New European Driving Cycle (NEDC) and the newly designed Athens Driving Cycle (ADC). Results show that $\mathrm{NO}_{x}$ emissions are higher in ADC than ECE and EDC, up to 2.5 times. Higher $\mathrm{CO}$ emissions are recorded during ADC for 1.6L and 2.0L cars while ECE-15 gave the higher $\mathrm{CO}$ emissions for the 2.4L vehicle. Overall $\mathrm{HC}$ emissions do not show any significant variation. Fuel consumption is higher for ADC mode in all cases.
\end{abstract}

KEYWORDS: NEDC, ADC, Driving Cycles, chassis dynamometer, exhaust emissions, fuel consumption 


\section{INTRODUCTION}

Traffic is one of the main sources of atmospheric pollution in cities around the globe and Athens is no exception. The tremendous increase of transportation vehicles resulted in serious traffic problems consisting of frequent stops and intense driving (vigorous accelerations and decelerations). Vehicles are responsible for almost all of the Carbon Monoxide (CO) emissions, for about the $75 \%$ of the Hydrocarbon $(\mathrm{HC})$ emissions and volatile organic compounts (VOC), and for about the $65 \%$ of the Nitrogen Oxide (NOx) emissions[1].

According to the APHEA programme (Air Pollution on Health-a European Approach) for Athens, the concequences of pollutants on the people's health are devastating even if their concentration in air is below the safety levels [2]. The estimation of pollutants and the emission prediction for the European countries (CORINAIR programme) is based on specific software like COPERT III [3] and FOREMOVE (FORecast of the Emissions from MOtor VEhicles)[4]. MEET project (Methodologies for Estimating air Pollutant Emissions from Transport), has developed a data base consisting of measurements on exhaust emission coefficients collected from various laboratories [5]. These coefficients are used by the COPERT software.

Emissions from vehicles are affected by the driving patterns which mainly depend on traffic conditions. "Driving Cycles" have been developed to provide a speed-time profile that is representative of urban driving [6]. They are used to assimilate driving conditions on a laboratory chassis dynamometer for the evaluation of fuel consumption, the exhaust emissions and emission coefficient [7].

There are two major categories of driving cycles, legislative and non-legislative. According to legislative driving cycles, Exhaust Emission Specifications are imposed by governments for the car Emission Certification. Such cycles are the FTP-75 [8] used in the USA the NEDC used in Europe and the 10-15 used in Japan. Non-legislative cycles, such as the Hong Kong driving cycle [9], the Sydney driving cycle and the herein presented Athens driving cycle, find broad application in research for energy conservation and pollution evaluation.

There are two ways of developing a driving cycle. One is composed from various driving modes of constant acceleration, deceleration and speed (like the NEDC and ECE), and is referred as modal or polygonal [10]. The other type is derived from actual driving data and is referred as "real world" cycle. Such cycles are the FTP-75 and the ADC. The real world cycles are more dynamic, reflecting the more rapid acceleration and deceleration patterns experienced during on road conditions. This more dynamic driving in real world conditions results on higher emissions compared to those under the standard emission (modal) test cycles [11].

The standardized inspections are official procedures of measuring fuel consumption and emissions. They are in force since 1970 and are frequently updated. The directive 70/220/EU, describes the procedure that all new types of vehicles have to follow, for their emission certification. The driving cycle used by the EU countries for the certification of passenger cars and light trucks, consists of four segments of ECE-15 (also known as Urban Driving Cycle: UDC) and the Extra Urban Driving Cycle (EUDC). The procedure is also called New European Driving Cycle (NEDC) after it was converted to cold start procedure by eliminating idling procedure i.e. emission sampling procedure starts at the same time that engine starts. This change was accomplished in the beginning of 2000. ECE-15 cycle is representative of city driving conditions in a typical European city (eg. Paris and Rome). EUDC simulates high speed driving and is applied directly after the fourth segment of ECE-15 (Figure 1).

The NEDC gives information about the vehicle operation in high speeds and an overall estimation of the emitted pollutants. However, there is poor correlation with real driving patterns and their effects on fuel consumption and emissions. The differences of Athens compared to other EU cities, as far as the infrastructure, the road network and the public transportation system is concerned, imposes the need to develop a representative driving cycle for more accurate evaluation of the exhaust emissions and the fuel consumption. 


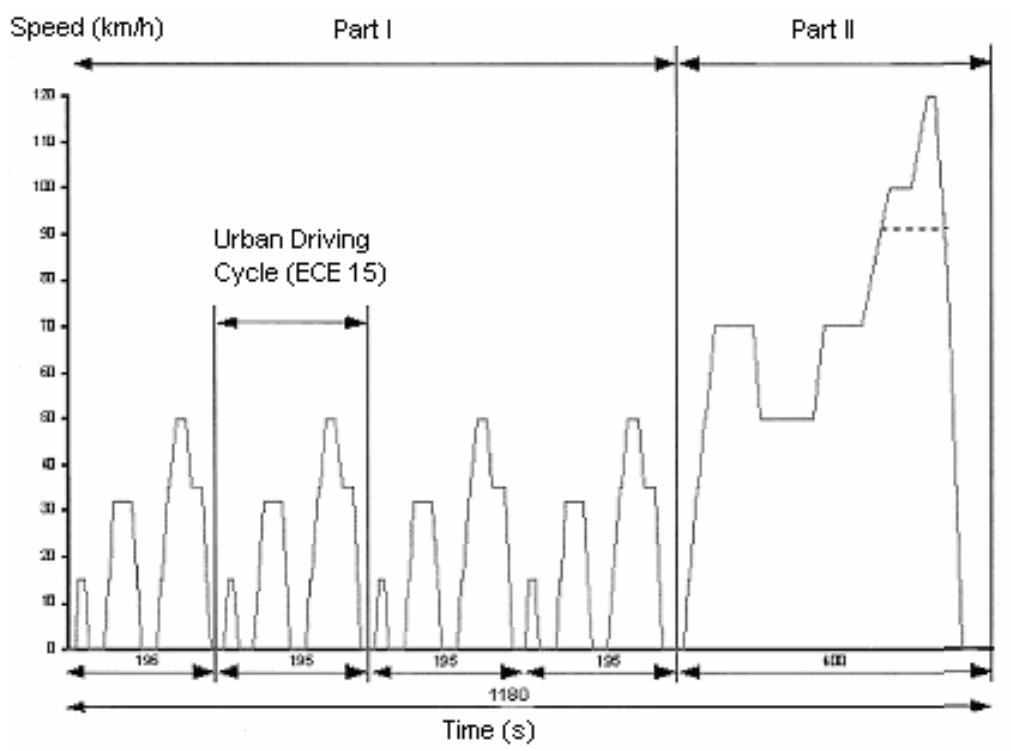

Figure 1. NEDC

\section{METHODOLOGY}

\subsection{Athens Driving Cycle (ADC) development}

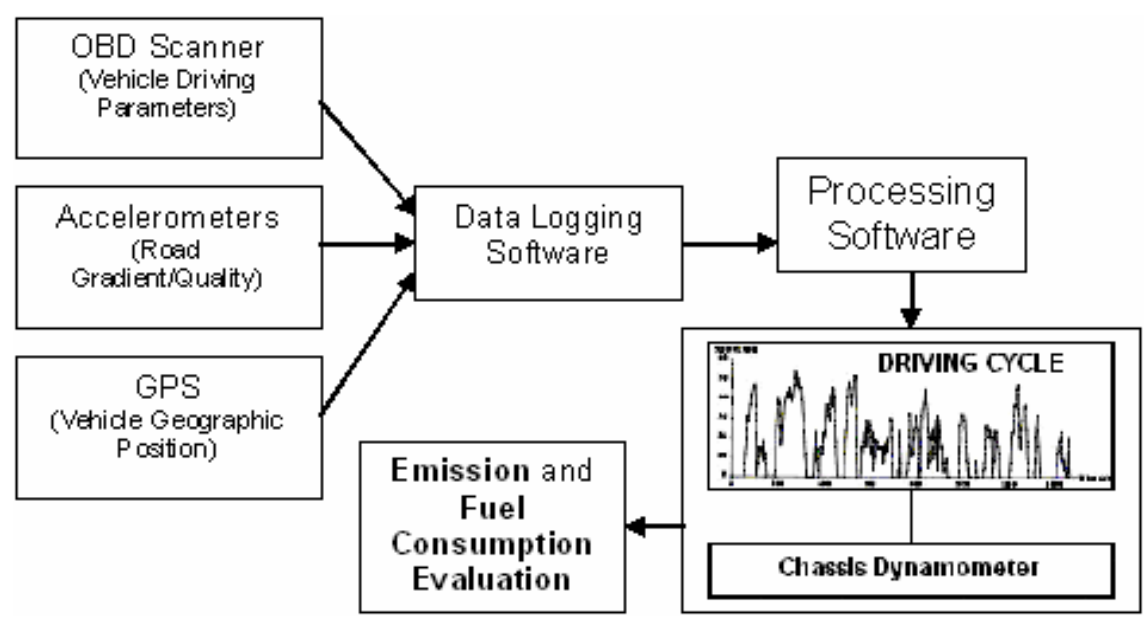

Figure 2. Flow chart of the procedure adopted for ADC development and emission measurement

Driving data was collected in the whole area of the Attica basin seven days a week from 6:00 until 24:00. The number of samples in each time zone is proportionate to the traffic density according to information from the Ministry of Environment Physical Planning and Public Works [12]. The "chase car" method was applied for the collection of driving data [13], [14].

The test vehicles are typical passenger cars of different engine capacity, equipped with a GPS receiver (Global Positioning System), an accelerometer, an OBD information recording (On Board Diagnosis reader), synchronized by a lap-top computer [15].

The distance of the driving cycle that is to be developed for a specific city, should be according to a representative distance that vehicles cover in that specific city. The distance chosen for $A D C$ development is equal to the mean route length per cold start that vehicles cover in Athens. This overall distance is equal to $6.9 \mathrm{~km}$ for the urban area[16]. This distance was reduced by $5 \%$ because on the one hand the recordings took place in the urban as well as the suburban area of Athens were the traveling speeds are higher and on the other hand the cycle should have duration that can be easily compared with the EDC.

Several methods were used in the past in order to process the huge amount of the on-road driving characteristics of the test vehicles [10], [17]. 
In this project, data were statistically processed using specially developed software taking into account parameters such as the topographical characteristics of the Attica basin (road slope) and other relative studies [18], [20] and the Athens Driving Cycle for 2002 (ADC 2002) was derived (Figure 3). Also extreme phases were removed such as very high top speed phases. Only the vital phases were kept to be processed and finally give the resulting ADC. The characteristics of the cycle match the overall summary characteristics of the data up to $99 \%$. It consists of 16 phases of various durations. Idle time in the ADC seize a large proportion of cycle time, cruising time is just non-existent and the vigorous changes in traveling speed describe the aggressive way that passenger cars are being driven in the specific city.

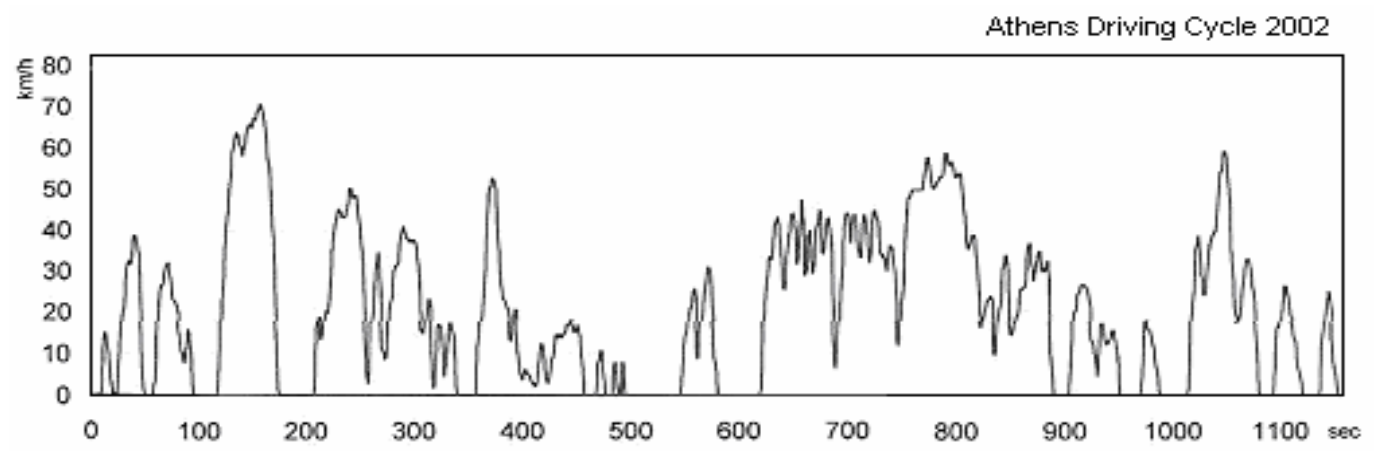

Figure 3. The Athens Driving Cycle, using actual traffic data during 2002 (ADC 2002)

\subsection{Emission Measurements}

The vehicles used for this study were passenger cars of three different categories. A Cintroen Xsara with $1.6 \mathrm{~L}$ engine, a Mitsubishi Space Runner with $2.0 \mathrm{~L}$ engine and a Chrysler Cruiser with $2.4 \mathrm{~L}$ engine were used.

The emission testing was carried out according to the standard procedure described in the EC directives (70/220/EC and 80/1268/EC) [20].

Three distinctive Driving Cycles on a laboratory chassis dynamometer were applied: the Urban Driving Cycle (ECE-15), the New European Driving Cycle (NEDC) and the newly modeled Athens Driving Cycle (ADC). The purpose was to compare ADC emissions against the emissions generated by performing the modal cycles used for emission certification by the EU. The pollutants measured include $\mathrm{HC}, \mathrm{CO}, \mathrm{CO}_{2}, \mathrm{NOx}\left(\mathrm{g} \mathrm{km}^{-1}\right)$ together with the fuel consumption (L/100 km) [20].

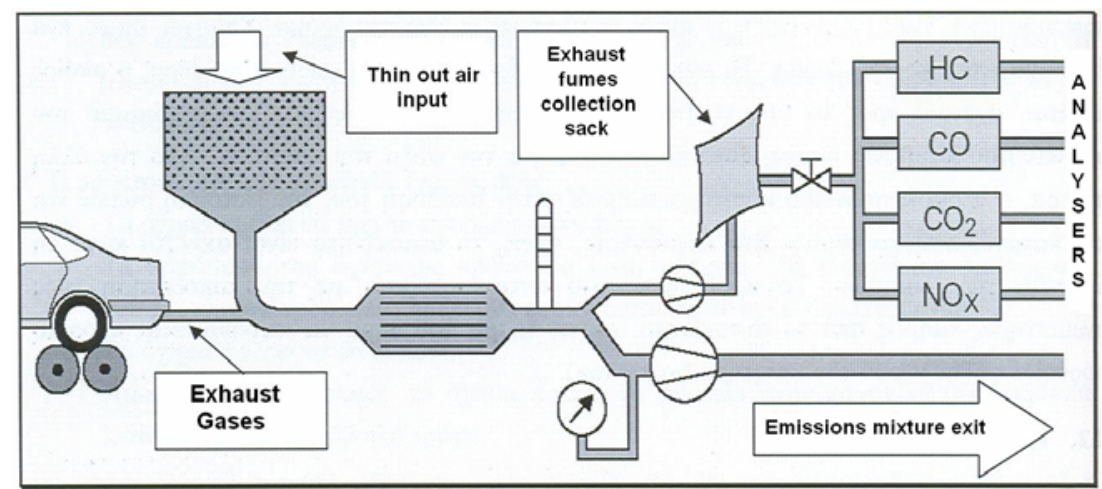

Figure 4. Emission measurement laboratory installation

\section{RESULTS}

\subsection{Cycle Comparison}

As can be seen in table 1, the characteristics of ADC 2002 vary greatly from those of the NEDC. The traveling speeds are significantly lower in ADC than NEDC (about 40\%). More rapid acceleration and deceleration are observed in ADC than NEDC. Almost half distance is covered in the same time bracket when driving on ADC. Acceleration for NEDC is nonrepresentative of any real traffic conditions of any city in the world. Real world driving cycles 
present much more rapid accelerations than accelerations presented in NEDC $\left(60 \mathrm{~km} \mathrm{~h}^{-1}\right.$ in 20 seconds).

Table 1. Typical parameters of ECE 15, EUDC, NEDC and ADC (2002 data)

\begin{tabular}{c|c|c|c|c}
\hline & ECE 15 & EUDC & NEDC & ADC \\
\hline Distance & $4 \times 1,013=4052 \mathrm{~m}$ & $6955 \mathrm{~m}$ & $11007 \mathrm{~m}$ & $6512 \mathrm{~m}$ \\
\hline Duration & $4 \times 195=780 \mathrm{sec}$ & $400 \mathrm{sec}$ & $1180 \mathrm{sec}$ & $1160 \mathrm{sec}$ \\
\hline Mean Speed & $18.7 \mathrm{~km} \mathrm{~h}^{-1}$ & $62.6 \mathrm{~km} \mathrm{~h}^{-1}$ & $33.6 \mathrm{~km} \mathrm{~h}^{-1}$ & $20.21 \mathrm{~km} \mathrm{~h}^{-1}$ \\
\hline Max. Speed & $50 \mathrm{~km} \mathrm{~h}^{-1}$ & $120 \mathrm{~km} \mathrm{~h}^{-1}$ & $120 \mathrm{~km} \mathrm{~h}^{-1}$ & $70.86 \mathrm{~km} \mathrm{~h}^{-1}$ \\
\hline
\end{tabular}

${ }^{1}$ Maximum speed is $90 \mathrm{~km} \mathrm{~h}^{-1}$ for low power vehicles.

\subsection{Emission and Fuel Consumption Comparison}

Comparison of NEDC, ECE 15 and ADC concerning emission and Fuel Consumption results for the three vehicles are presented on Table 2.

Table 2. Emissions of vehicles measured for all three driving cycles

\begin{tabular}{|c|c|c|c|c|c|}
\hline \multicolumn{6}{|c|}{ Cintroen Xsara 1.6} \\
\hline \multirow{2}{*}{$\begin{array}{l}\text { Pollutants } \\
\left(\mathrm{g} \mathrm{km}^{-1}\right)\end{array}$} & \multicolumn{3}{|c|}{ Driving Cycles } & \multicolumn{2}{|c|}{$\begin{array}{c}\text { ADC in relation } \% \\
\text { to }\end{array}$} \\
\hline & NEDC & ECE & ADC & NEDC & ECE \\
\hline $\mathrm{HC}$ & 0,01 & 0,01 & 0,01 & 0 & 0 \\
\hline $\mathrm{CO}$ & 0,24 & 0,19 & 0,36 & +50 & +90 \\
\hline $\mathrm{NO}_{\mathrm{x}}$ & 0,02 & 0,03 & 0,08 & +300 & +165 \\
\hline $\mathrm{CO}_{2}$ & 214,18 & 314,60 & 343,54 & +60 & +9 \\
\hline $\begin{array}{c}\text { F.Consumption } \\
(\mathrm{L} / 100 \mathrm{~km})\end{array}$ & 9,01 & 13,23 & 14,45 & +60 & +9 \\
\hline \multicolumn{6}{|c|}{ Mitsubishi Space Runner 2.0} \\
\hline \multirow{2}{*}{$\begin{array}{l}\text { Pollutants } \\
\left(\mathrm{g} \mathrm{km}^{-1}\right)\end{array}$} & \multicolumn{3}{|c|}{ Driving Cycles } & \multicolumn{2}{|c|}{$\begin{array}{c}\text { ADC in relation } \% \\
\text { to }\end{array}$} \\
\hline & NEDC & ECE & ADC & NEDC & ECE \\
\hline $\mathrm{HC}$ & 0,15 & 0,17 & 0,24 & +60 & +41 \\
\hline $\mathrm{CO}$ & 3,79 & 3,80 & 8,80 & +132 & +132 \\
\hline $\mathrm{NO}_{\mathrm{x}}$ & 0,36 & 0,59 & 0,69 & +92 & +17 \\
\hline $\mathrm{CO}_{2}$ & 378,98 & 543,73 & 588,37 & +55 & +8 \\
\hline $\begin{array}{l}\text { F.Consumption } \\
(\mathrm{L} / 100 \mathrm{~km})\end{array}$ & 16,14 & 23,09 & 25,22 & +56 & +9 \\
\hline \multicolumn{6}{|c|}{ Chrysler PT Cruiser 2.4} \\
\hline \multirow{2}{*}{$\begin{array}{l}\text { Pollutants } \\
\left(\mathrm{g} \mathrm{km}^{-1}\right)\end{array}$} & \multicolumn{3}{|c|}{ Driving Cycles } & \multicolumn{2}{|c|}{$\begin{array}{c}\text { ADC in relation \% } \\
\text { to }\end{array}$} \\
\hline & NEDC & ECE & $A D C$ & NEDC & ECE \\
\hline $\mathrm{HC}$ & 0,01 & 0,03 & 0,01 & 0 & -67 \\
\hline $\mathrm{CO}$ & 0,27 & 1,18 & 0,45 & +67 & -62 \\
\hline $\mathrm{NO}_{\mathrm{x}}$ & 0,06 & 0,08 & 0,15 & +150 & +79 \\
\hline $\mathrm{CO}_{2}$ & 341,27 & 533,87 & 610,79 & +60 & +14 \\
\hline $\begin{array}{l}\text { F.Consumption } \\
(\mathrm{L} / 100 \mathrm{~km})\end{array}$ & 14,35 & 22,52 & 25,68 & +79 & +9 \\
\hline
\end{tabular}

Fuel consumption is increased during tests in ADC from $56 \%$ for Space Runner, up to $79 \%$ for the PT Cruiser, compared to EDC. The increase for Xsara is $60 \%$. There is a smaller increase recorded, compared to urban driving cycle, which in all cases is $9 \%$ (Figure 5). 


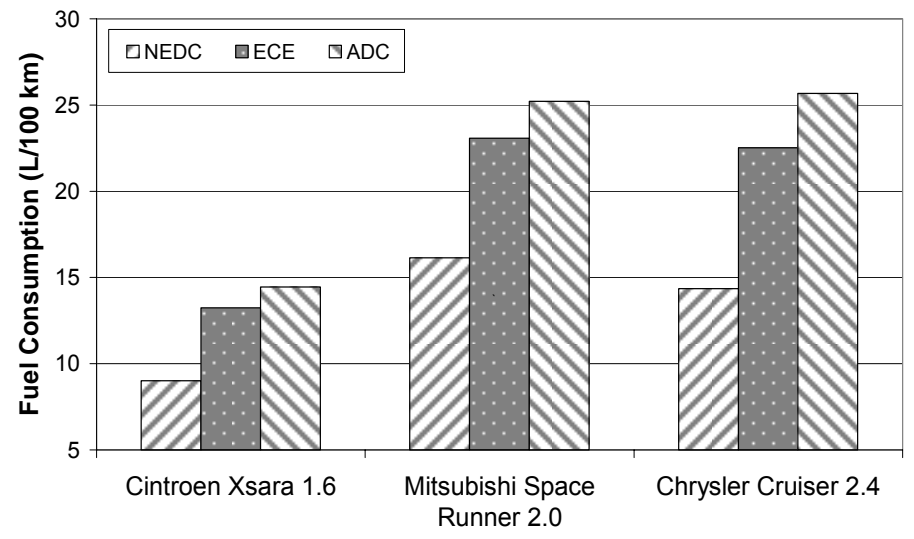

Figure 5. Fuel Consumption measured for all three vehicles

Similar increase is observed for $\mathrm{CO}_{2}$ emission which is a pollutant that is directly related to fuel consumption. Thus for Xsara the increase is $60 \%$ compared to EDC and $9 \%$ compared to urban driving cycle. The corresponding figures for the Space Runner are $55 \%$ and $8 \%$ and for the PT Cruiser are $79 \%$ and $14 \%$ respectively.

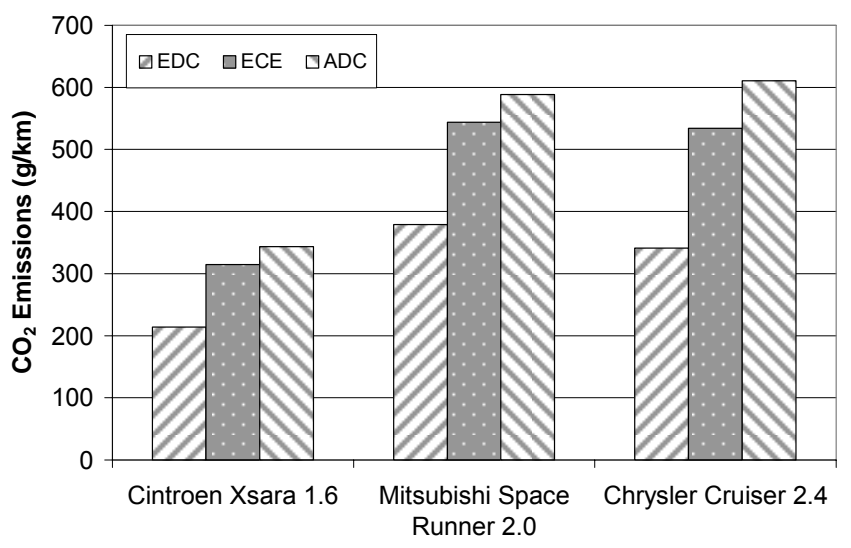

Figure 6. $\mathrm{CO}_{2}$ Emissions

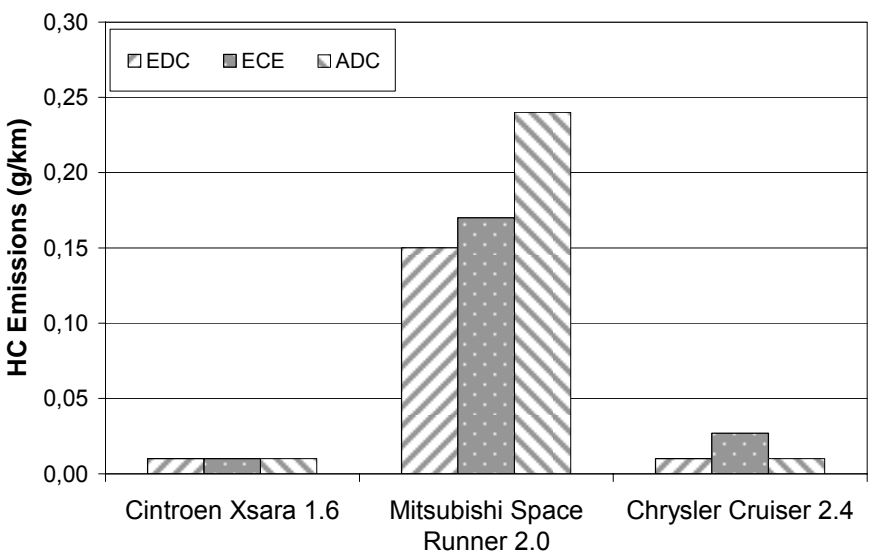

Figure 7. HC Emissions 


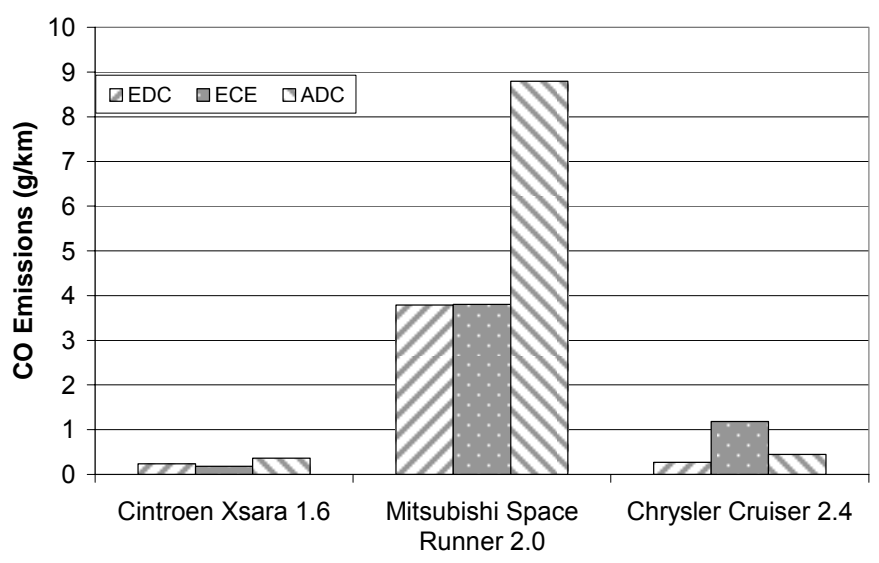

Figure 8. CO Emissions

Hydrocarbon emissions showed minor changes between the cycles. Only in the case of Space Runner significant changes were observed. A safe conclusion could not be established for the other two vehicles, due to the very small differences in the absolute values.

As far as Carbon monoxide emissions are concerned, those vary depending on the cycle. There was a decrease of about $62 \%$ for PT Cruiser (ADC compared to urban). Appositively, Space Runner shows an increase of $132 \%$ when comparing ADC with both the EDC and the urban driving cycle.

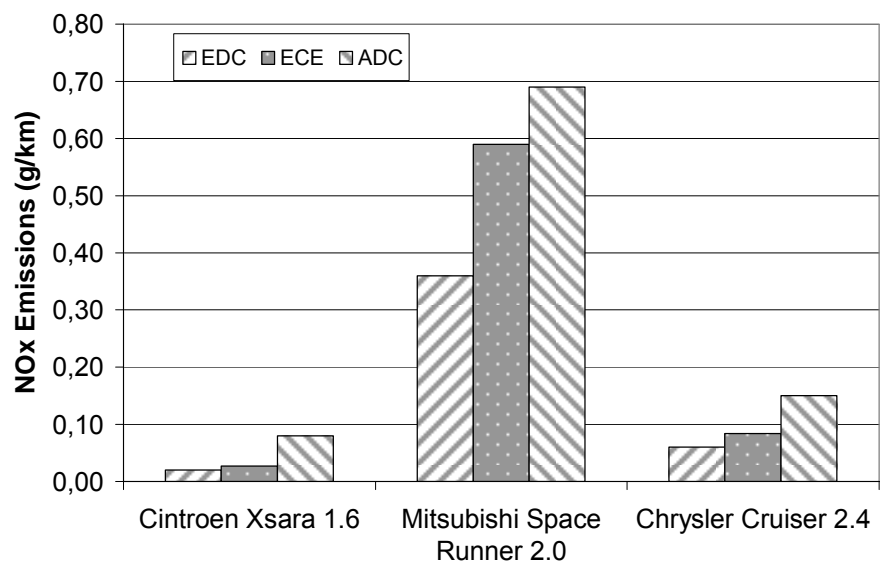

Figure 9. NOx Emissions

Nitrogen oxide emissions vary from about $100 \%$ to $300 \%$ higher for ADC relatively to NEDC and from $15 \%$ to $200 \%$ relatively to ECE 15 . The biggest changes come from the Xsara and the smallest from Space Runner in opposition to the absolute values of the emissions as can be seen in figure 9 .

\section{CONCLUSIONS}

Emission and fuel consumption measurements showed significant variations between ADC and the European driving cycles, verifying the exceptionality of Athens. Fuel consumption showed an increase for ADC compared to ECE and NEDC in percentages that vary from $9 \%$ to about $79 \%$ depending on the vehicle. Exhaust emissions were also measured to be increasing for ADC (0\% to 300\%) with a few exceptions for $\mathrm{HC}$ and $\mathrm{CO}$ measured on PT Cruiser. It is therefore evident that the European driving cycle is not suitable for the emission and fuel consumption estimation for vehicles (passenger cars) driven in Attica basin. Development of driving cycles like ADC 2002 for Athens Basin, gives more suitable, representative and thus accurate prediction models. 
Driving patterns should be constantly updated with new traffic data recordings due to the alterations of the road network, the growing and changing of the car fleet, the traffic adjustments and changing driving behaviour.

The comparison of Athens driving conditions with European and Urban driving cycles used for emissions certification in European countries is done in order to stress out the differences on that field. Despite that Greece is a European country; no traffic data from any city were included when the certification cycles were developed.

They should be included in the future or every country in the EU should precede to the development of individual driving cycles (according to their unique driving conditions) for their own emissions testing and certification procedures.

\section{ACKNOWLEDGMENTS}

The present work is accomplished under the project "HRAKLEITOS". The Project "HRAKLEITOS" is co-funded by the European Social Fund (75\%) and National Resources $(25 \%)$.

Also this project would not have been accomplished without the support and kind offer of a number of car retail companies and especially Audi, Honda, Mazda and Seat.

\section{REFERENCES}

1. Ministry of Environment, Physical Planning and Public Works (1989) EARTH-PERPA Administration, Atmospheric Pollution in the Athens Area, Volume 1-4, Athens, March 1989.

2. EC project, sponsored by the EC science and research directorate, DGXII, APHEA (Air Pollution on Health - a European Approach) 1977 - 1992 in Amsterdam, Athens, Barcelona, Bratislava, Cologne, Krakow, Helsinki, Lodz, London, Lyon, Milan, Paris, Poznan, Rotterdam and Wroclaw.

3. European Environment Agency/European Topic Centre on Air Emission (1999), COPERT III, 'Computer Programme to Calculate Emissions from Road Transport'.

4. Andrias A., Timpanidis I., Zahariadis Th., Samaras Z. (1997) Emission Prediction from Road Transport in Greece during 1990-2010, Scientific Edition TEE - IV, 4(2), 7-22.

5. MEET (1999), Methodology for calculation transport emissions and energy consumption. Transport research fourth framework programmme. Strategic research. DG VII-99. European Communities, 1999, Luxembourg.

6. Lyons T.J., Kenworthy J.R., Austin P.I., Newman P.W.G. (1986). The development of a driving cycle for fuel consumption and emission evaluation, Transportation Research, 20A(6), 447462.

7. Simanaitis D.J. (1977) Emission test cycles around the world, Automotive Engineering, 85, 3443.

8. DieselNet, Emission Test Cycles-Summary of worldwide engine and vehicle test cycles, URL:http://www.dieselnet.com/standards/cycles/ftp75.html

9. Tong H.Y., Hung W.T., Cheung C.S. (1999) Development of a driving cycle for Hong Kong. Atmospheric Environment, 33, 2323-2335

10. Kuhler M., Karstens D. (1978). Improved driving cycle for testing automotive exhaust emissions. SAE Technical Paper, Series 780650.

11. OECD (2004), Can Cars Come Clean? Strategies for low-emission vehicles, OECD publications, Paris

12. Ministry of Environment Physical Planning and Public Works, (2003) Traffic detailed measurements $2000-2002$, Athens, Greece

13. Ergeneman M., Sorusbay C., Goktan A., (1997). Development of a driving cycle for the prediction of pollutant emissions and fuel consumption. International Journal of Vehicle Design, 18, 391-399.

14. Austin T., DiGenova F.J., Carlson T.R., Joy R.W., Gianolini K.A. and Lee J.M. (1993). Characterization of Driving Patterns and Emissions from Light-Duty Vehicles in California, The Final Report. Sacramento, California: Air Research Board, A932-185.

15. Ericson E. (1997), How to measure driving patterns - A study of methodology, 4th International Symposium "Transport and Air Pollution", Avignon 9-13 June 1997/ actes affiches, Inrets, Bron, France, p.125-130.

16. Pitsas K., Zannikos F., Stournas S., Lois E., Karonis D. (2003) New Technologies for the Evaluation of the environmental impact from vehicles in Attica Basin, Proceedings from Chemical Engineering Convention, Patra, May 2003. 
17. Kruse R.E., Huls T.A. (1973) Development for the federal urban driving cycle, SAE Paper, 730553.

18. Kiriakis N. (1998) Engine Start Conditions correlated to the use of Passenger Cars in Athens, Scientific Edition TEE, 18(2), 49-57

19. Teng H., Yu L. (2001), Analytical Tool for Measuring Emission Impact of Accel/Decel. (Prepared for New Jersey Department of Transportation), April 1, 2001

20. Pitsas K.A. (2003), PhD research, Vehicle Technical Inspenction. Driving Cycles and Atmospheric Pollution, National Technical University of Athens, School of Chemical Engineering, Athens, Greece. 